\title{
DISCRIMINANT ANALYSIS THROUGH FISHER'S METHOD OF THE LEVEL OF INTEREST IN TOURIST ATTRACTIONS IN INDONESIA
}

\author{
Khairul Umam ${ }^{1}$ \\ ${ }^{1}$ Department of mathematic Education, Syiah Kuala University \\ E-mail: Khumam77@unsyiah.ac.id
}

Diterima: 12/08/2020; Disetujui: 31/08/2020

\begin{abstract}
ABSTRAK
Penelitian ini bertujuan untuk mengelompokkan 100 tempat wisata yang ada di Indonesia kedalam daerah tempat wisata yang menarik dan tidak menarik untuk dikunjungi menggunakan software SPSS. Data tersebut dinormalkan menggunakan fungsi "sqrt" kemudian dianalisis menggunakan diskriminan fishers melalui SPSS. Data yang menjadi variabel dependen adalah keadaan menarik atau tidaknya suatu tempat wisata terhadap variabel-variabel yang mempengaruhi. Hasil yang diperoleh dari analisis ini berupa terdapatnya 50 tempat wisata yang menarik untuk dikunjungi dan 50 tempat wisata yang tidak menarik untuk dikunjungi. Fungsi diskriminan linier fisher yang terbentuk adalah.

Tempat wisata yang menarik untuk dikunjungi:

$\mathrm{Y} 1=0,523 \mathrm{X} 1+(-3,610) \mathrm{X} 2+2,176 \mathrm{X} 3+5,071 \mathrm{X} 4+9,728 \mathrm{X} 5+8,865 \mathrm{X} 6+(-0,440) \mathrm{X} 7+11,012 \mathrm{X} 8+$ $5,596 \mathrm{X} 9+3,086 \mathrm{X} 10+(-0,881) \mathrm{X} 11+2,352 \mathrm{X} 12+(-1,251) \mathrm{X} 13+3,944 \mathrm{X} 14+15,624 \mathrm{X} 15$

Dan tempat wisata yang tidak menarik untuk dikunjungi:

$\mathrm{Y} 2=(-0,095) \mathrm{X} 1+(-2,552) \mathrm{X} 2+2,081 \mathrm{X} 3+3,130 \mathrm{X} 4+6.602 \mathrm{X} 5+5,330 \mathrm{X} 6+(-0,88) \mathrm{X} 7+8,333 \mathrm{X} 8+$ $3,276 \mathrm{X} 9+3,907 \mathrm{X} 10+(-0,462) \mathrm{X} 11+2,246 \mathrm{X} 12+0,214 \mathrm{X} 13+3,842 \mathrm{X} 14+9,042 \mathrm{X} 15$
\end{abstract}

Kata Kunci: analisis diskriminan, fisher,tempat wisata. 


\begin{abstract}
This study aims to classify 100 tourist attractions in Indonesia into an interesting tourist areas and not interesting to visit using SPSS software. The data is normalized using the "sqrt" function and then analyzed using discriminant fishers via SPSS. The data becomes the dependent variable is the state of interest or not a tourist attraction to the variables that affect. The results obtained from this analysis in the form of 50 interesting sights to visit and 50 tourist attractions that are not interesting to visit.

The linear discriminant function that formed interesting places to visit is: $Y 1=0,523 X 1+(-3,610) X 2+2,176 X 3+5,071 X 4+9,728 X 5+8,865 X 6+(-0,440) X 7+$ $11,012 \times 8+5,596 \times 9+3,086 \times 10+(-0,881) \times 11+2,352 \times 12+(-1,251) X 13+$ $3,944 X 14+15,624 X 15$

And uninteresting attractions to visit is:

$\begin{aligned} Y 2= & (-0,095) X 1+(-2,552) X 2+2,081 X 3+3,130 X 4+6.602 X 5+5,330 X 6+(-0.88) X 7+ \\ & 8.333 X 8+3.276 X 9+3,907 X 10+(-0,462) X 11+2,246 X 12+0,214 X 13+3,842 X 14+ \\ & 9,042 X 15\end{aligned}$
\end{abstract}

Keywords:Discriminant Analysis, Fisher, Places of Interest. 
Analisis Diskriminan Terhadap Tingkat Ketertarikan Tempat Wisata Di Indonesia Menggunakan Metode Fishers Khairul Umam

\section{PENDAHULUAN}

Analisis Diskriminan adalah teknik multivariat yang termasuk pada Dependence Method, dengan ciri adanya variabel dependen dan independen (Santoso, 2002). Dengan demikian, ada variabel yang hasilnya tergantung pada data variabel independen. Model Analisis Diskriminan ditandai dengan ciri khusus yaitu data variabel dependen yang harus berupa data kategori, sedangkan data independen justru berupa data non kategori.

Pariwisata mempunyai peran yang sangat penting dalam pembangunan Indonesia khususnya sebagai salah satu penghasil devisa negara (Mamuko, Lengkong, \& Pombengi, 2018). Di samping sebagai mesin penggerak ekonomi, pariwisata adalah aktivitas yang menarik untuk mengurangi angka pengangguran (Wispandono, 2011). Dalam perekonomian nasional, pariwisata merupakan salah satu sektor yang diharapkan mampu memberikan peningkatan pendapatan melalui penerimaan devisa (Fauzia, 2018). Pariwisata merupakan sektor yang terus menerus dikembangkan pemerintah sebagai pilar pembangunan nasional karena mampu menopang perekonomian nasional pada saat dunia sedang mengalami krisis (Pajriah, 2018). Dalam Undang-Undang nomor 10 tahun 2009 dinyatakan bahwa pembangunan kepariwisataan diperlukan untuk mendorong pemerataan kesempatan berusaha dan memperoleh manfaat serta mampu
Jurnal Geuthèë: Penelitian Multidisiplin Vol. 03, No. 02, (Agustus, 2020), pp. 453-464.

menghadapi tantangan perubahan kehidupan lokal, nasional dan global.

Pengembangan kepariwisataan juga bertujuan untuk memperkenalkan keindahan alam dan kebudayaan Indonesia. Ini berarti, pengembangan pariwisata di Indonesia tidak terlepas dari potensi yang dimiliki Indonesia untuk mendukung pariwisata tersebut. Indonesia memiliki keragaman budaya yang sangat menarik. Keragaman budaya ini dilatari oleh adanya agama, adat istiadat yang unik, dan kesenian yang dimiliki oleh setiap suku yang ada di Indonesia.

Wisatawan umumnya mengunjungi tempat wisata untuk menyegarkan pikiran ataupun sekedar mengisi waktu luang. Mereka menetukan tempat wisata dengan mendapatkan informasi dari berbagai sumber. Adakalanya informasi yang diperoleh tidak sesuai dengan yang diharapkan. Hal ini akan mengakibatkan wisatawan merasa kecewa melihat tempat wisata yang ia kunjungi. Berdasarkan uraian di atas penulis akan memberikan informasi tentang tempat wisata apa sajakah yang tergolong tempat yang menarik atau tidak menarik untuk dikunjungi di Indonesia menggunakan metode Fishers.

Berdasarkan latar belakang di atas adapun hal yang mendasari penelitian ini adalah bagaimana pengelompokan tempat wisata yang ada di Indonesia berdasarkan kriteria menarik atau tidak menarik melalui analisis diskriminan berbantuan software SPSS? 


\section{METODE PENELITIAN}

\section{1) Syarat-Syarat Menggunakan Analisis Diskriminan}

Menurut Dillon W.R \& Goldstein.M, (1984), syarat-syarat yang harus dipenuhi untuk menggunakan teknik analisis ini diantaranya ialah :

1. Variabel tergantung hanya satu dan bersifat non-metrik, artinya data harus dikategorikan dan berskala nominal.

2. Variabel bebas terdiri dari dua variabel.

3. Semua kasus harus dependent.

4. Semua variabel predictor sebaiknya mempunyai distribusi normal multivariat, dan matrices variance-covariance dalam kelompok harus sama untuk semua kelompok.

5. Keanggotaan kelompok diasumsikan eksklusif.

\section{2) Analisis Diskriminan Fisher}

Metode linear fisher sebenarnya berasal daristatistik klasifikasi linear untuk dua populasi normal. Penyusunan fungsi diskriminan Fisher dilakukan dengan membentuk kombinasi linear dari peubah-peubah yang diamati yang akan memberikan nilai keragaman sekecil mungkin bagi objek-objek dalam kelompok yang sama dansebesar mungkin bagi objek-objek antar kelompok. Selanjutnya peubah-peubah yang signifikan dipilih untuk dimasukkan ke dalam penyusunan model diskriminan dengan menggunakan uji independensi (Kathleen. M, \& Carmen. A, 2002)

\section{3) Model Diskriminan Linier Fisher}

Analisis ini didasarkan atas fungsi diskriminan yang mempunyai bentuk umum:

$$
Y_{-} i=\beta_{-} 0+\beta_{-} 1 X \_1+\beta_{-} 2 X \_2+\cdots+\beta_{-} p X \_p+\varepsilon_{-} I
$$

Johnson, R, A, and D. W. Wichern dalam Wahyuni (2011) menjelaskan bahwa analisis diskriminan Fisher merupakan salah satu metode dalam mendapatkan fungsi diskriminan. Pada metode ini pengamatan multivariat $\mathrm{X}$ ditransformasikan kepengamatan univariat $\mathrm{Y}$ dimana Y berasal dari populasi pertama dan kedua untuk dipisahkan sebanyak mungkin untuk pengamatan lainnya. Fisher's menyarankan untuk mengambil kombinasi linier dari $\mathrm{X}$ untuk menghasilkan $\mathrm{Y}$ yang merupakan suatu fungsi yang cukup sederhana untuk pemasangan dari $\mathrm{X}$.

\section{HASIL PENELITIAN DAN PEMBAHASAN}

Data yang telah didapat oleh peneliti yang bersumber dari Pusat Pariwisata Indonesia merupakan data mentah yang variannya jauh berbeda. Oleh karenanya, data tersebut harus diubah menjadi normal terlebih dahulu, sehingga varian dari masing- 
Analisis Diskriminan Terhadap Tingkat Ketertarikan

Tempat Wisata Di Indonesia Menggunakan Metode Fishers Khairul Umam

masing variabel tempat wisata di dalam data tersebut menjadi homogen.

Berikut adalah data mentah yang telah ditabulasikan (lihat Tabel 1).
Jurnal Geuthèë: Penelitian Multidisiplin Vol. 03, No. 02, (Agustus, 2020), pp. 453-464. 


\section{Tabel 1. Data Tempat Wisata di Indonesia yang Menarik dan Tidak Menarik untuk Dikunjung}




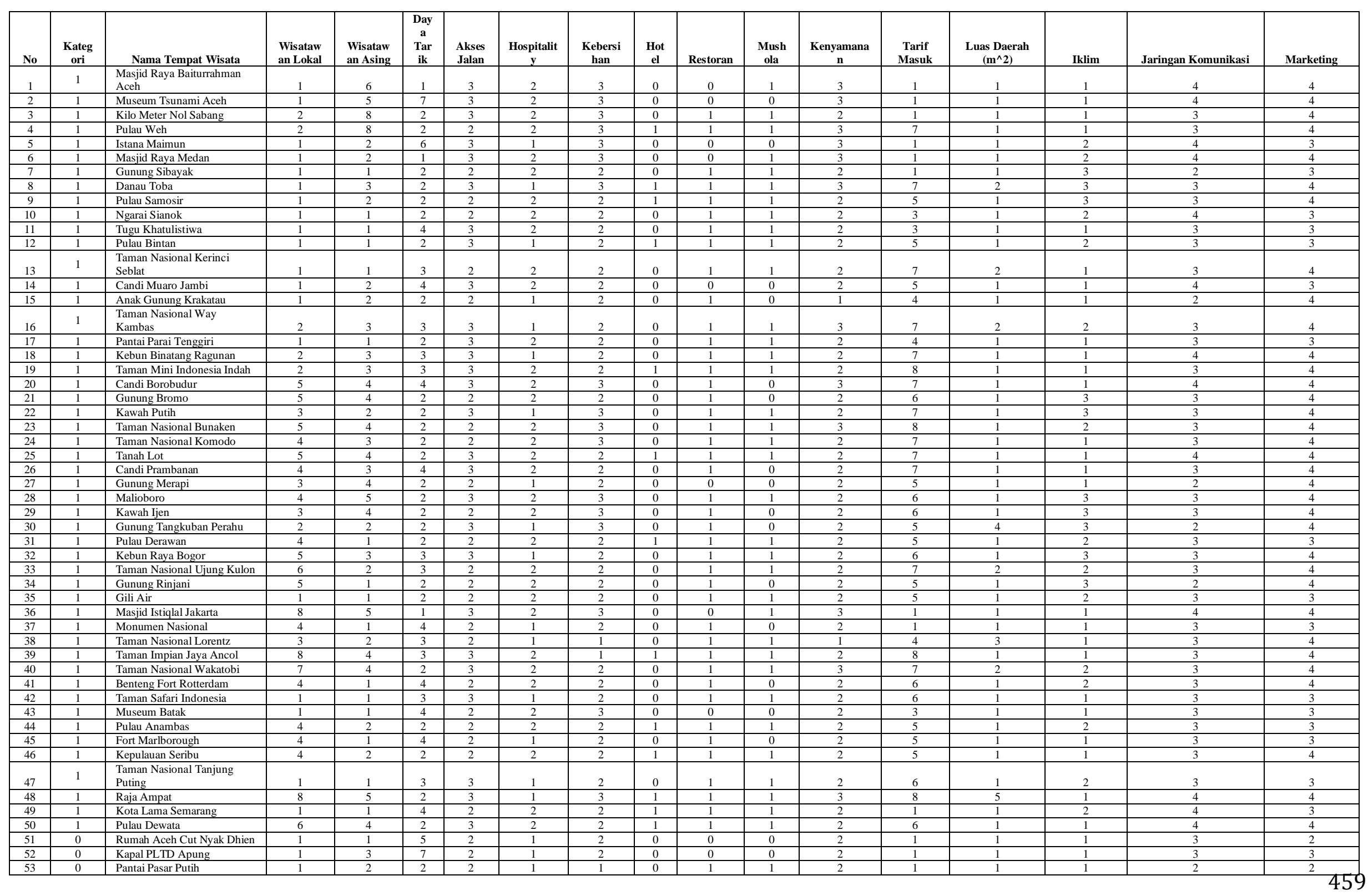




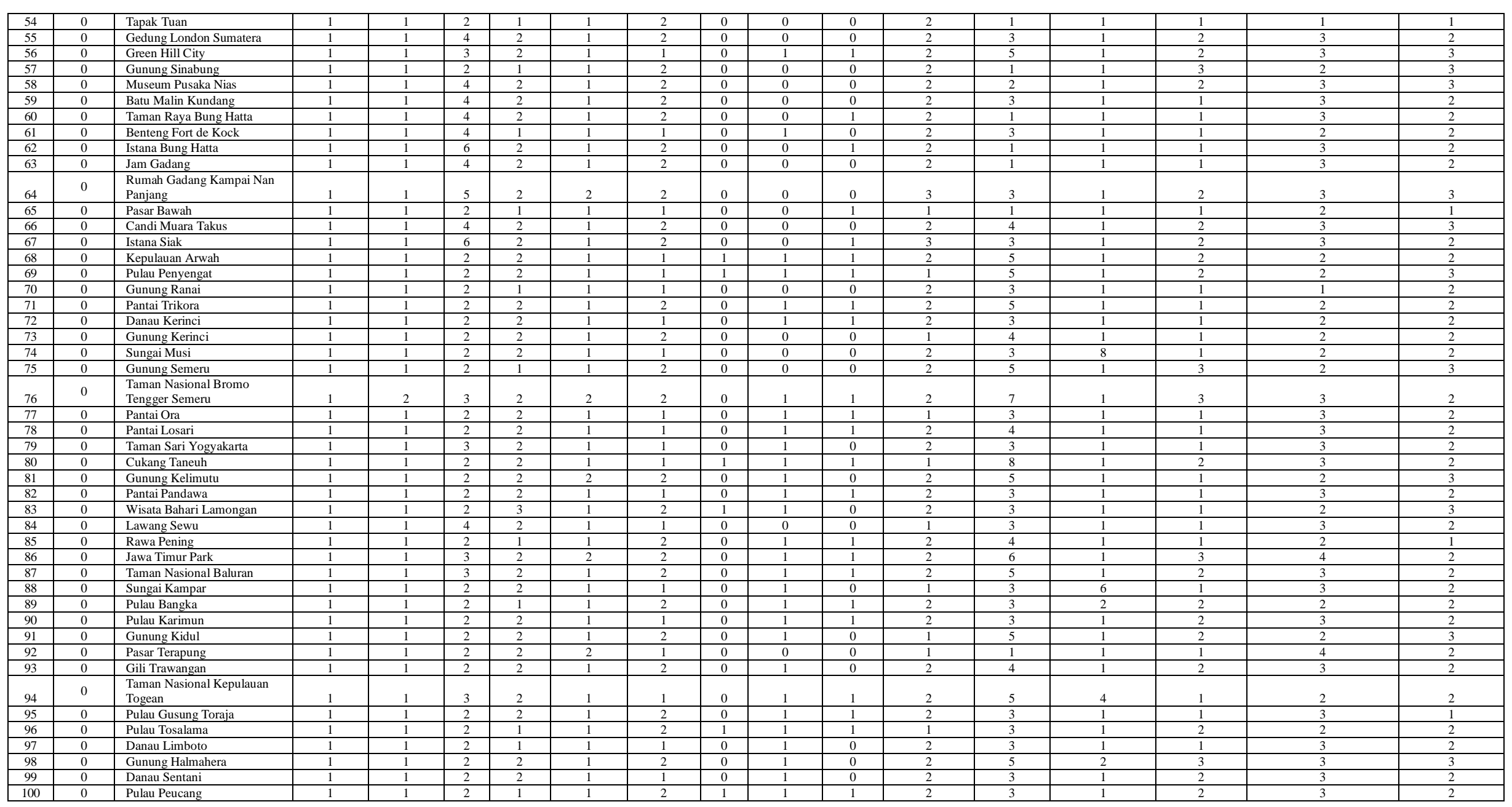

Sumber: Survey peneliti dari Pusat Pariwisata dan berbagai Website 
Analisis Diskriminan Terhadap Tingkat Ketertarikan Tempat Wisata Di Indonesia Menggunakan Metode Fishers Khairul Umam

Pada penelitian ini, Peneliti menormalkan beberapa variabel bencana menggunakan fungsi "sqrt" dengan bantuan software SPSS.

Kemudian data yang telah dinormalkan tersebut dianalisis dengan discriminant fishersdimana grouping variable yang diambil adalah menarik atau tidaknya suatu tempat wisata untuk dikunjungi. Berikut adalah deskripsi data yang diolah dengan discriminant fishers (lihat Gambar 1) yang menunjukkan pengelompokan tempat wisata:

\begin{tabular}{|l|r|r|}
\hline \multicolumn{2}{|c|}{ Classification Function Coefficients } \\
\cline { 2 - 3 } & \multicolumn{2}{|c|}{ Kategori } \\
\cline { 2 - 3 } & Tidak menarik & Menarik \\
\hline wisatawan lokal &,- 095 &, 523 \\
wisatawan asing & $-2,552$ & $-3,610$ \\
daya tarik & 2,081 & 2,176 \\
akses jalan & 3,130 & 5,071 \\
hospitality & 6,602 & 9,728 \\
kebersihan & 5,330 & 8,865 \\
hotel &,- 088 &,- 440 \\
restoran & 8,333 & 11,012 \\
mushola & 3,276 & 5,596 \\
kenyamanan & 3,907 & 3,086 \\
tarif masuk &,- 462 &,- 881 \\
luas daerah & 2,246 & 2,352 \\
iklim &, 214 & $-1,251$ \\
jaringan komunikasi & 3,842 & 3,944 \\
marketing & 9,042 & 15,624 \\
(Constant) & $-35,400$ & $-67,424$ \\
\hline
\end{tabular}

Fisher's linear discriminant functions

Berdasarkan gambar diatas, diperoleh model untuk pengelompokan daerah tempat wisata yang menarik dan tidak menarik untuk dikunjungi yaitu sebagai berikut:
Jurnal Geuthèë: Penelitian Multidisiplin Vol. 03, No. 02, (Agustus, 2020), pp. 453-464.

\section{1) Tempat Wisata yang Menarik untuk Dikunjungi}

$$
\begin{aligned}
& 0,523 X_{1}+(-3,610) X_{2}+2,176 X_{3}+5,071 X_{4}+ \\
& 9,728 X_{5}+8,865 X_{6}+(-0,440) X_{7}+11,012 X_{8}+ \\
& 5,596 X_{9}+3,086 X_{10}+(-0,881) X_{11}+2,352 X_{12}+ \\
& (-1,251) X_{13}+3,944 X_{14}+15,624 X_{15}=0
\end{aligned}
$$

\section{2) Tempat Wisata yang Tidak Menarik untuk Dikunjungi}

$$
\begin{aligned}
& (-0,095) X_{1}+(-2,552) X_{2}+2,081 X_{3}+3,130 X_{4}+ \\
& 6.602 X_{5}+5,330 X_{6}+(-0,88) X_{7}+8,333 X_{8}+ \\
& 3,276 X_{9}+3,907 X_{10}+(-0,462) X_{11}+2,246 X_{12}+ \\
& 0,214 X_{13}+3,842 X_{14}+9,042 X_{15}=0
\end{aligned}
$$

Dimana :

$\mathrm{X}_{1}=$ wisatawan lokal

$\mathrm{X}_{2}=$ wisatawan asing

$\mathrm{X}_{3}=$ daya tarik

$\mathrm{X}_{4}=$ akses jalan

$\mathrm{X}_{5}=$ hospitality

$\mathrm{X}_{6}=$ kebersihan

$\mathrm{X}_{7}=$ hotel

$\mathrm{X}_{8}=$ restoran

$\mathrm{X}_{9}=$ mushola

$\mathrm{X}_{10}=$ kenyamanan

$\mathrm{X}_{11}=$ tarif masuk

$\mathrm{X}_{12}=$ luas daerah

$\mathrm{X}_{13}=\mathrm{iklim}$

$$
\begin{aligned}
& \mathrm{X}_{14}=\text { jaringan komunikasi } \\
& \mathrm{X}_{15}=\text { marketing }
\end{aligned}
$$


Sebagai contoh, Sebagai contoh, misalkan ada tempat wisata Q1 dengan nilai wisatawan lokal 1, nilai wisatwan asing6, nilai daya tarik1, nilai akses jalan3, nilai hospitality 2, nilai kebersihan3, nilai hotel 0 , nilai restoran 0 , nilai mushola 1 , nilai kenyamanan 3 , nilai tarif masuk 1, nilai luas daerah 1 , nilai iklim 1 , nilai jaringan komunikasi 4, dan nilai marketing 4. Hal ini dapat disajikan menjadi $X_{1}=1$; $X_{2}=6 ; X_{3}=1 ; X_{4}=3 ; X_{5}=2 ;$ dan $X_{6}=3, X_{7}=0 ; X_{8}=0 ; X_{9}=1 ; X_{10}=3$; $X_{11}=1 ; X_{12}=1 ; X_{13}=1 ; X_{14}=4$ dan $X_{15}=4$.

Substitusikan ke fungsi diskriminan maka akan diperoleh :
Mengacu pada hasil penelitian ini diperoleh beberapa kesimpulan, diantaranya:

1. Indonesia memiliki banyak tempat wisata dengan perbandingan tempat wisata yang menarik dan tidak menarik ialah 50:50. Hal ini ditunjukkan oleh hasil perhitungan penelitian melalui fungsi diskriminan linier fisher dengan bantuan software SPSS (versi 16.0).

2. Fungsi diskriminan Fisher yang diperoleh melalui software SPSS (versi 16.0) adalah:

$$
\begin{aligned}
Y_{\text {menarik }} & =0,523 \mathrm{X} 1+(-3,610) \mathrm{X} 2+ \\
& 2,176 \mathrm{X} 3+5,071 \mathrm{X} 4+9,728 \mathrm{X} 5 \\
& +8,865 \mathrm{X} 6+(-0,440) \mathrm{X} 7+
\end{aligned}
$$$$
11,012 \times 8+5,596 \times 9+3,086 \times 10
$$$$
+(-0,881) \mathrm{X} 11+2,352 \mathrm{X} 12+(-
$$

$Y_{\text {menarik }}=135,649$

$\mathrm{Y}_{\text {tidak menarik }}=(-0,095) \mathrm{X} 1+(-2,552) \mathrm{X} 2+$

$Y_{\text {ak menarik }}=-0,095(1)-2,552(6)+2,081(1)+3,130(3)+6,081 X 3+3,130 X 4+6.602 X 5$ $-0,88(0)+8,333(0)+3,276(1)+3,907(3)-0,465,(33) \times 12,246(1) 0,88) \times 7+$ $+0,214(1)+3,842(4)+9,042(4$

$Y_{\text {tidak menarik }}=93,789$

$8,333 \times 8+3,276 \times 9+$

$3,907 \times 10+(-0,462) \times 11+$

Hasil di atas menunjukkan $2,246 \times 12+0,214 \times 13+$ $Y_{\text {menarik }}>Y_{\text {tidak menarik }}$, sehingga tempat

3. Penelitian ini berguna untuk menentukan wisata Q1 masuk ke dalam kelompok tempat wisata yang menarik. suatu daerah tergolong kedalam kelompok mana, subtitusikan nilai setiap variabelnya kedalam 2 model diatas.

\section{SIMPULAN} Nilai yang terbesar dari kedua persamaan adalah kelompok dari daerah yang diuji. 


\section{DAFTAR PUSTAKA}

Dillon W.R \& Goldstein.M, (1984), Multivariate Analysis Method and Application, Sons, New york.

Fauzia, M. (2018). Kejar Pendapatan Devisa dari Pariwisata, Ini 9 Langkah Pemerintah. Yogyakarta: Kompas.com.Johnson, R, A, and D. W. Wichern, (1988), Applied Multivariate Statistical Analysis, Prentice Hall, Inc, New jersey

Johnson, R, A, and D. W. Wichern, (1988), Applied Multivariate Statistical Analysis, Prentice Hall, Inc, New jersey

Kathleen. M, \& Carmen. A, (2002), SPSS for instutional researchers, Bucknell University.

Kleinbaum, R, A, \& L.L. Kupper, (1978), Applied Multivariate Analysis and Other Multivariate Methods, Ruxbury Press, Massachusects.

Mamuko, E. N., Lengkong, F. D., \& Pombengi, J. (2018). Kebijakan Pemerintah Daerah dalam Mengembangkan Obyek Wisata di Kabupaten Sutaro. Jurnal Administrasi Publik .

Pajriah, S. (2018). Peran Sumber Daya Manusia dalam Pengembangan Pariwisata Budaya di Kabupaten Ciamis. Jurnal Artefak: History and Education .

Santoso, Singgih. 2002. Buku Latihan SPSS Statistik Multivariat. Jakarta: Elex Media Komputindo.

Umam, Khairul, Yuhasriati, Nadya. 2015. Analisis Diskriminan Melalui Metode Fisher Terhadap Kemampuan Siswa dalam Menguasai Materi Bangun Ruang pada Kelas VIII SMPN 1 Banda Aceh Tahun Pelajaran 2013/2014. Jurnal Natural, Vol. 15, No. 1

Umam, K. (2018). Analisis Diskriminan Melalui Metode Fisher Terhadap Mahasiswa Hukum dalam Memilih Profesi. Jurnal Geuthèe .

Wahyuni, Vera. 2011. Analisis Diskriminan Fisher untuk Membedakan Tingkat Penguasaan Bahasa Inggris Mahasiswa FMIPA Unsyiah. Banda Aceh: Universitas Syiah Kuala. Skripsi.

Wispandono, R. M. (2011). Upaya Mengurangi Pengangguran Melalui Peningkatan Wisata Kuliner (Studi Pada Pedagang Kaki Lima di Surabaya). Journal Unipdu .

http://download.portalgaruda.org/article.php?articleANALISIS PARTISIPASI MASYARAKAT DALAM_PENGEMBANGAN_DESA_WISATA

http://www.kemenpar.go.id/userfiles/Wisnus\%202014.pdf

https://www.google.co.id/url?sa=t\&rct=j\&q=\&esrc=s\&source=web\&cd=1\&cad=rja\&uact=8\&ved= 0ahUKEwiJ1rukpJXYAhWBvY8KHZ_mAfoQFggoMAA\&url=http\%3A\%2F\%2Fetd.rep 
ository.ugm.ac.id\%2Fdownloadfile\%2F113673\%2Fpotongan\%2FS1-2017-352318introduction.pdf\&usg=AOvVaw131tt386EN3MrvYVWtWg8G 